\title{
Preparation of mitochondria to measure superoxide flashes in angiosperm flowers
}

\author{
Chulan Zhang Equal first author, 1 ，Fengshuo Sun Equal first author, 2 , Biao Xiong ${ }^{3}$ ， Zhixiang Zhang ${ }^{\text {Corresp. } 1}$ \\ ${ }^{1}$ College of Nature Conservation, Beijing Forestry University, Beijing, China \\ 2 College of Biological Sciences and Biotechnology, Beijing Forestry University, Beijing, China \\ 3 College of Tea Science, Guizhou University, Guizhou Province, China \\ Corresponding Author: Zhixiang Zhang \\ Email address: zxzhang@bjfu.edu.cn
}

Background Mitochondria are the center of energy metabolism and the production of reactive oxygen species (ROS). ROS production results in a burst of "superoxide flashes", which is always accompanied by depolarization of mitochondrial membrane potential. Superoxide flashes have only been studied in the model plant Arabidopsis thaliana using a complex method to isolate mitochondria. In this study, we present an efficient, easier method to isolate functional mitochondria from floral tissues to measure superoxide flashes.

Method We used $0.5 \mathrm{~g}$ samples to isolate mitochondria within $<1.5 \mathrm{~h}$ from flowers of two nontransgenic plants (Magnolia denudata and Nelumbo nucifera) to measure superoxide flashes. Superoxide flashes were visualized by the $\mathrm{pH}$-insensitive indicator MitoSOX Red, while the mitochondrial membrane potential $(\Delta \Psi \mathrm{m})$ was labelled with TMRM.

Results Mitochondria isolated using our method showed a high respiration ratio. Our results indicate that the location of ROS and mitochondria was in a good coincidence. Increased ROS together with a higher frequency of superoxide flashes was found in mitochondria isolated from the flower pistil. Furthermore, a higher rate of depolarization of the $\Delta \Psi_{\mathrm{m}}$ was observed in the pistil. Taken together, these results demonstrate that the frequency of superoxide flashes is closely related to depolarization of the $\Delta \Psi_{\mathrm{m}}$ in petals and pistils of flowers. 


\section{Preparation of mitochondria to measure superoxide}

\section{2 flashes in angiosperm flowers}

3

4 Chulan Zhang ${ }^{1}$, Fengshuo Sun², Biao Xiong ${ }^{3}$, and Zhixiang Zhang ${ }^{1}$

$5 \quad{ }^{1}$ College of Nature Conservation, Beijing Forestry University, Beijing, China

$6 \quad{ }^{2}$ College of Biological Sciences and Biotechnology, Beijing Forestry University, Beijing, China

$7 \quad{ }^{3}$ College of Tea Science, GuiZhou University, GuiZhou Province, China

\section{Corresponding author:}

Zhixiang Zhang, Ph.D. 
24

25

26

27

\section{Abstract}

Background Mitochondria are the center of energy metabolism and the production of reactive oxygen species (ROS). ROS production results in a burst of "superoxide flashes", which is always accompanied by depolarization of mitochondrial membrane potential. Superoxide flashes have only been studied in the model plant Arabidopsis thaliana using a complex method to isolate mitochondria. In this study, we present an efficient, easier method to isolate functional mitochondria from floral tissues to measure superoxide flashes.

Method We used $0.5 \mathrm{~g}$ samples to isolate mitochondria within $<1.5 \mathrm{~h}$ from flowers of two nontransgenic plants (Magnolia denudata and Nelumbo nucifera) to measure superoxide flashes. Superoxide flashes were visualized by the $\mathrm{pH}$-insensitive indicator MitoSOX Red, while the mitochondrial membrane potential $(\Delta \Psi \mathrm{m})$ was labelled with TMRM.

Results Mitochondria isolated using our method showed a high respiration ratio. Our results indicate that the location of ROS and mitochondria was in a good coincidence. Increased ROS together with a higher frequency of superoxide flashes was found in mitochondria isolated from the flower pistil. Furthermore, a higher rate of depolarization of the $\Delta \Psi \mathrm{m}$ was observed in the pistil. Taken together, these results demonstrate that the frequency of superoxide flashes is closely related to depolarization of the $\Delta \Psi \mathrm{m}$ in petals and pistils of flowers. 


\section{Introduction}

Mitochondria are widely distributed organelles in eukaryotic cells where they perform

53 important roles generating energy, regulating physiological activities, and maintaining cellular metabolism (Hatefi 1985; Yang et al. 2018). The major role of mitochondria is the generation of ATP by oxidative phosphorylation through the electron transport chain (Hatefi 1985). In addition to energy production, mitochondria are also the center of reactive oxygen species (ROS) production in organisms under biotic or abiotic stress (Paital and Chainy 2014; Yang et al. 2016). The isolation of mitochondria has deepened research on metabolism and stress in plants (Day et al. 1985). In 1985, mitochondria from $300 \mathrm{~g}$ of pea leaves were isolated and purified by centrifugation on a Percoll gradient containing a linear gradient of polyvinylpyrrolidone-25 (0$10 \%, \mathrm{w} / \mathrm{v}$ ) to obtain only $20 \mathrm{mg}$ mitochondrial protein (Day et al. 1985). After that, mitochondria were isolated from Arabidopsis thaliana using differential centrifugation and further purified using a continuous colloidal density gradient (Lyu et al. 2018; Sweetlove et al. 2007). In addition, crude isolation of mitochondria in leaves using density gradient centrifugation revealed higher respiratory coupling than that observed in purified mitochondria (Keech et al. 2005). It is well known that mitochondria must be purified to extract mitochondrial DNA and the proteome (Ahmed and Fu 2015; Kim et al. 2015), but the time required and the sampling method were not suitable in many mitochondrial studies, particularly in non-green tissues such as flowers. Crude isolation of the intact and functional mitochondria is crucial for the measurement of superoxide flashes in plants.

Superoxide flashes are 10-s events that occur spontaneously and suddenly in mitochondria and reflect electrical and chemical activities (Feng et al. 2017). Superoxide flashes were first defined as transient events of the mitochondrial matrix-targeted biosensor mt-cp YFP (Wei and 
Dirksen 2012). As mt-cp YFP is sensitive to $\mathrm{pH}$, superoxide flashes can be visualized by chemical probes, including ROS indicators, such as MitoSOX for superoxide and 2.7dichlorodihyfrofluorescein (DCF) for $\mathrm{H}_{2} \mathrm{O}_{2}$ (Feng et al. 2017; Zhang et al. 2013). Interestingly, cp-YFP superoxide flashes are correlated with depolarization of the mitochondrial membrane potential $\left(\Delta \Psi_{\mathrm{m}}\right)$ (Zhang et al. 2013). Previous studies have shown that ROS modulate a variety of physiological events, including growth, stress, thermogenesis, and diseases (Jastroch 2017; Keunen et al. 2015; Kuznetsov et al. 2017; Maksimov et al. 2018; Yang et al. 2016). It is clear that the accumulation of ROS are closely associated with superoxide flashes. In animals, superoxide flashes and ROS bursts are involved in various physiological activities, such as oxidative stress, metabolism, and aging (Pouvreau 2010; Wei et al. 2011). Thus, there is a close relationship between superoxide flashes and mitochondrial energy metabolism. Considering the importance of the mitochondrial respiratory chain and energy metabolism, it is of great significance to study mitochondrial superoxide flashes in plants.

Superoxide flashes have been well studied in cells and isolated mitochondria of animals, and the cp YFP-flash signals are always associated with the loss of $\Delta \Psi_{\mathrm{m}}$ (labeled with TMRM) (Li et al. 2012). Superoxide flashes observed with the chemical probes MitoSOX and DCF reveal the same results and frequency as cp YFP flashes (Zhang et al. 2013). In plant tissues, superoxide flashes have only been studied in the roots of Arabidopsis and the cp-YFP signals changed with different respiratory substrates (Schwarzlander et al. 2011), but no study has explored superoxide flashes in other non-transgenic tissues of plants. Floral tissues in plants are important organs involved in various physical activities, including thermogenesis, pollination, and reproduction (Luo et al. 2010; Thien et al. 2009). Mitochondrial energy metabolism and oxygen consumption are closely related to floral thermogenesis and reproduction (Miller et al. 2011); thus, it is necessary to combine the activity of mitochondrial superoxide flashes with a study of floral reproduction in plants. As isolating plant mitochondria using a previous method was likely to influence mitochondrial viability and the mitochondrial-targeted cp-YFP is hardly expressed in 
102

103

104

105

106

107

108

109

110

111

112

113

114

115

116

117

118

119

120

\section{1}

122

123

124

125

126

127

128

xylophyta flowers, a suitable method to study superoxide flashes in floral tissues is crucial.

To address these issues, some important modifications were devised based on previous methods to study superoxide flashes (Zhang et al. 2013). We developed an efficient method to isolate high viability mitochondria in floral tissues of Magnolia denudata and Nelumbo nucifera. As these are non-transgenic flowers, superoxide flashes were first visualized by loading the plants with MitoSOX Red, while the $\Delta \Psi_{\mathrm{m}}$ was labelled with TMRM. These methods facilitated study of mitochondrial energy metabolism and physiological activities in non-transgenic flowers of angiosperms. This quick and sample-saving protocol greatly improved the viability of mitochondria and efficiency of the experiment of superoxide flashes in non-green plant tissues.

\section{Materials \& Methods}

\section{Plant materials/plant growth}

M. denudata was grown on the campus of Beijing Forestry University $\left(40^{\circ} 00^{\prime} 02^{\prime \prime} \mathrm{N}\right.$, $116^{\circ} 20^{\prime} 15^{\prime \prime}$, a.s.1., $60 \mathrm{~m}$ ). Pistils and petals of 15 flowers were collected during afternoons in March and April. N. nucifera was grown in Bajia Country Park (4000'50"N, 116 $16^{\circ} 39^{\prime \prime} \mathrm{E}$, a.s.1., $47 \mathrm{~m})$. Receptacles and petals of nearly 10 flowers were collected during afternoons in JulyAugust.

\section{Solutions}

Method A: Grinding buffer: $0.3 \mathrm{M}$ sucrose, $25 \mathrm{mM} \mathrm{Na}_{4} \mathrm{P}_{2} \mathrm{O}_{4}, 2 \mathrm{mM}$ EDTA, $10 \mathrm{mM}$ $\mathrm{KH}_{2} \mathrm{PO}_{4}, 1 \%(\mathrm{w} / \mathrm{v})$ polyvinylpyrrolidone-40, 1\% (w/v) defatted bovine serum albumin (BSA), 4 $\mathrm{mM}$ cysteine, and $20 \mathrm{mM}$ ascorbic acid were added just prior to grinding. $\mathrm{pH}$ was adjusted to 7.5 with $\mathrm{KOH}$. Resuspension buffer: $0.3 \mathrm{M}$ sucrose, $10 \mathrm{mM} \mathrm{N}$-Tris [hydroxymethyl]-methyl-2aminoethanesulfonic acid (TES-KOH), and 0.1\% BSA, $\mathrm{pH}=7.5$. Mitochondrial basic incubation medium: 0.3 M sucrose, $10 \mathrm{mM}$ TES-KOH. $10 \mathrm{mM} \mathrm{NaCl,} 5 \mathrm{mM} \mathrm{KH}_{2} \mathrm{PO}_{4}, 2 \mathrm{mM} \mathrm{MgSO}$, and $0.1 \% \mathrm{BSA}, \mathrm{pH}=7.2$. 
129

130

131

132

133

134

135

136

137

138

139

140

141

142

143

144

145

146

147

148

149

150

151

152

153

154

155

Method B: Grinding buffer: $0.3 \mathrm{M}$ sucrose, $25 \mathrm{mM} \mathrm{Na}_{4} \mathrm{P}_{2} \mathrm{O}_{4}, 2 \mathrm{mM}$ EDTA, $10 \mathrm{mM}$

$\mathrm{KH}_{2} \mathrm{PO}_{4}, 1 \%(\mathrm{w} / \mathrm{v})$ polyvinylpyrrolidone- $40,1 \%(\mathrm{w} / \mathrm{v})$ defatted bovine serum albumin (BSA) and $20 \mathrm{mM}$ ascorbic acid were added just prior to grinding. $\mathrm{pH}$ was adjusted to 7.5 with $\mathrm{KOH}$. Resuspension buffer: $0.3 \mathrm{M}$ sucrose and 10mM TES-KOH, $\mathrm{pH}=7.5$. Preparation of a single linear PVP-40 gradient in 28\% (v/v) Percoll: $0.3 \mathrm{M}$ sucros, $10 \mathrm{mM} \mathrm{KH}_{2} \mathrm{PO}_{4}, 0.1 \%$ BSA, 28\% (v/v) Percoll and a linear gradient of 0-10\% (w/v) PVP-40 (top to bottom) in a $30 \mathrm{ml}$ centrifuge tube. $\mathrm{pH}=7.2$. Mitochondrial basic incubation medium: $0.3 \mathrm{M}$ sucrose, $10 \mathrm{mM}$ TES-KOH. 10 $\mathrm{mM} \mathrm{NaCl}, 5 \mathrm{mM} \mathrm{KH}_{2} \mathrm{PO}_{4}, 2 \mathrm{mM} \mathrm{MgSO}$, and 0.1\% BSA, $\mathrm{pH}=7.2$.

\section{Isolation of mitochondria}

Method A: Our efficiency method to obtain crude, high viability mitochondria. All steps were carried at $4^{\circ} \mathrm{C}$ on ice. Mitochondria of magnolia were isolated from style and petal tissues while mitochondria of lotus were isolated from receptacle and petal tissues. About $0.5 \mathrm{~g}$ of pistil or petal tissues were cut up from each species into $1 \mathrm{~mm}^{3}$-fragments with scissors. They were ground in 1-2 $\mathrm{ml}$ of grinding buffer using a pestle with a small amount of quartz. The extract was filtered through $20 \mu \mathrm{m}$ nylon mesh and then centrifuged at 2,000 $\times \mathrm{g}$ for $10 \mathrm{~min}$ to remove most of the thylakoid membranes and intact chloroplasts. The supernatant was transferred to a new tube and centrifuged at $12,000 \times \mathrm{g}$ for $20 \mathrm{~min}$. The pellet was resuspended in $1 \mathrm{ml}$ resuspension buffer and centrifuged for $5 \mathrm{~min}$ at $1,500 \times \mathrm{g}$ to remove the residual intact chloroplasts. This new supernatant was centrifuged for $20 \mathrm{~min}$ at $12,000 \times \mathrm{g}$ to yield the crude mitochondria. The crude mitochondria were suspended in mitochondrial basic incubation medium and placed on ice for further studies.

Method B: to obtain purified mitochondria as previous study. All steps were carried at $4^{\circ} \mathrm{C}$ on ice. Mitochondria were isolated from style of magnolia and receptacle of lotus. About $45 \mathrm{~g}$ of pistil tissues were cut up with scissors (see above). Isolation of mitochondria was based on the method of Sweetlove et al (2007) with minor modification. Briefly, pistil tissues were blended in $200 \mathrm{ml}$ grinding buffer (see above), filtered through $20 \mu \mathrm{m}$ nylon mesh and then centrifuged at 
156

157

158

159

160

161

162

163

164

165

166

167

168

169

170

171

172

173

174

175

176

177

178

179

180

181

182

183

$1,100 \times \mathrm{g}$ for $10 \mathrm{~min}$. The supernatant was centrifuged at $18,000 \times \mathrm{g}$ for $20 \mathrm{~min}$. The pellet was resuspended in $30 \mathrm{ml}$ resuspension buffer and centrifuged for $10 \mathrm{~min}$ at $1,100 \times \mathrm{g}$. This new supernatant was centrifuged for another $20 \mathrm{~min}$ at $18,000 \times \mathrm{g}$. The final pellet was suspended in $1 \mathrm{ml}$ resuspension buffer and layered over the linear PVP-40 gradient in 28\% (v/v) Percoll (see above), and centrifuged for $45 \mathrm{~min}$ at $40,000 \times \mathrm{g}$. The mitochondria were found in a tight white band near the bottom of tube. The mitochondria fraction was carefully removed and resuspended in $20 \mathrm{ml}$ resuspension buffer, the suspension was centrifuged for $20 \mathrm{~min}$ at $15,000 \times \mathrm{g}$. The purified mitochondria were suspended in mitochondrial basic incubation medium and place on ice for further studies.

\section{Mitochondrial respiratory function assay}

The oxygen consumption rates of mitochondria were determined with a Clark-type oxygen electrode (Strathkelvin 782 2-Channel Oxygen System version 1.0, Strathkelvin Instruments, Motherwell, UK) at $25^{\circ} \mathrm{C}$. A $10 \mu \mathrm{l}$ aliquot of mitochondrial suspension was blended in $1 \mathrm{ml}$ of mitochondrial basic incubation medium. The oxygen sensor signal was recorded on a computer at intervals of $0.5 \mathrm{~s}$ with Strathkelvin Instruments software (782 System version 1.0). Oxygen consumption was measured with $250 \mu \mathrm{M}$ ADP (state 3 ) and with $5 \mathrm{mM}$ succinate (state 4). The respiratory control ratio (RCR) was calculated as the ratio of state 3 to state 4 respiration. The mitochondrial suspensions with higher than a state 3 RCR were used in subsequent studies.

\section{Confocal imaging of Mito-ROS and $\Delta \Psi_{\mathrm{m}}$}

To visualize the superoxide flashes and $\Delta \Psi_{\mathrm{m}}$, isolated mitochondria from pistil and petal tissues of magnolia and lotus were immobilized on round glass cover slides (pretreatment with $0.2 \mathrm{mg} / \mathrm{ml}$ poly-L-lysine for $1 \mathrm{~h}$; Sigma, St. Louis, MO, USA) by centrifugation at 2,000 $\times \mathrm{g}$ for $5 \mathrm{~min}$ at $4^{\circ} \mathrm{C}$ and mounted on an inverted microscope (Zeiss LSM 710: Carl Zeiss, Oberkochen, Germany) for imaging. To measure the subcellular locations of mitochondria and ROS, mitochondria were first incubated with $100 \mathrm{nM}$ MitoTracker Green (Invitrogen, Carlsbad, CA, USA) for $30 \mathrm{~min}$ at $25^{\circ} \mathrm{C}$ and washed in mitochondrial basic incubation medium, then loaded 
184

185

186

187

188

189

190

191

192

193

194

195

196

197

198

199

200

201

202

203

204

205

206

207

208

209

210

with $2.5 \mu \mathrm{M}$ MitoSOX Red for $5 \mathrm{~min}$. MitoTracker Green was excited with $488 \mathrm{~nm}$ and emissions were collected at 500-530 nm, while MitoSOX Red was excited with $543 \mathrm{~nm}$ and collected at an emission wavelength of 560-620 nm. Isolated mitochondria were labelled with $2.5 \mu \mathrm{M}$ MitoSOX Red and $5 \mathrm{mM}$ succinate as a respiration substrate to measure superoxide flashes. To understand the MitoSOX-flashes behavior in the change of respiration state and uncoupler, 0.25 mM ADP and 5 $\mu \mathrm{M}$ FCCP (Carbonyl cyanide 4-(trifluoromethoxy) phenylhydrazone) was added to observe the superoxide flashes. Isolated mitochondria were loaded with $50 \mathrm{nM}$ TMRM and $5 \mathrm{mM}$ succinate for $1 \mathrm{~min}$ at $25^{\circ} \mathrm{C}$ to measure the $\Delta \Psi_{\mathrm{m}}$. The excitation wavelength for TMRM was 543 and the emission wavelength was $550-620 \mathrm{~nm}$. A total of 100 frames of $512 \times 512$ pixels were collected for a typical time-series recording. The frame rate was 50-60 frames/min. All experiments were performed at room temperature (24$\left.26^{\circ} \mathrm{C}\right)$.

\section{Data analysis}

The images obtained by laser scanning confocal microscopy were analyzed using Image $\mathrm{J}$ 1.48v (Wayne Rasband, National Institutes of Health, Bethesda, MD, USA). Superoxide flashes and variations in the $\Delta \Psi_{\mathrm{m}}$ were identified using FlashSniper (Li et al. 2012), and their morphological, properties, and duration were measured automatically. Statistical analyses were performed using SPSS Statistics 23.0 software (IBM Corp., Armonk, NY, USA). Images were processed and assembled using Adobe Photoshop CS 5 (Adobe Systems Corp., San Jose, CA, USA).

\section{Results}

\section{Respiratory function and viability of isolated mitochondria}

Crude mitochondria were sampled from petal and style tissues of magnolia as shown in Fig. 
211 1A, while mitochondria from petal and receptacle tissues of lotus were sampled as shown in Fig.

212 1F. A signal with excitation at $488 \mathrm{~nm}$ was confirmed to avoid the disturbing auto-fluorescence

213 of intact chloroplasts. As shown in Fig. 1B and G, no intact chloroplasts were detected in the

214 crude isolated mitochondria. To compare the previous method (method B) (Day et al. 1985) and

215 our efficient method (method A) to isolate mitochondria, the respiratory function of the isolated

216 mitochondria was determined with a Clark-type oxygen electrode. As a result, the RCR did not

217 change significantly in mitochondria isolated from flowers using method A $(n=6)$, but RCR

218 declined in isolated mitochondria using method B $(n=6)$ (Table 1). As the viability of

219 mitochondria is reflected by the $\Delta \Psi_{\mathrm{m}}$, crude isolated mitochondria were loaded with the TMRM

220 indicator. Highly viable and highly dense mitochondria were observed in mitochondria of

221 magnolia (Fig. 1C, D) and lotus (Fig. 1H, I). The viability of mitochondria using method B was

222 lower than that of method A (Fig. 1E, J). We assessed the time consumed, amount of sample

223 consumed, and the viability of both methods. Using method B, mitochondria were processed in

$2245.28 \pm 0.23 \mathrm{~h}$ and consumed $43.92 \pm 3.78 \mathrm{~g}$ of flower tissues $(\mathrm{n}=6)$, whereas mitochondria were

225 isolated within $1.13 \pm 0.14 \mathrm{~h}$ with only $0.47 \pm 0.12 \mathrm{~g}$ tissues $(\mathrm{n}=6)$ using our method A. This

226 result shows that our mitochondrial isolation method was highly efficient to obtain highly viable

227 mitochondria in the flower species.

228

229 ROS production in floral mitochondria

230 To identify the intracellular site of ROS production, mitochondrial ROS were loaded with

231

232

233

234

235

236

237

MitoSOX Red for $5 \min (2.5 \mu \mathrm{M})$, while mitochondria were loaded with Mito Tracker Green for $30 \min (100 \mathrm{nM})$. ROS production and mitochondrial location were coincident in the mitochondria isolated from petals and styles of magnolia, suggesting that mitochondria are the primary site of ROS production in this species (Fig. 2C, G). The same results were found in the mitochondria isolated from receptacle and petal of lotus (Fig. 2J, N).

The fluorescent level of ROS increased significantly in the mitochondria isolated from style compared to the petal of magnolia (Fig. 2B, D, F) $(n=100)$. In addition, similar results were 
238

239

240

241

242

243

244

245

246

247

248

249

250

251

252

253

254

255

256

257

258

259

260

261

262

263

264

found in the isolated mitochondria of lotus, as the ROS level was significantly higher in the receptacle than in the petal (Fig. 2I, K, M) $(n=100)$. Our results confirm that mitochondrial ROS tended to accumulate in the pistil of both magnolia and lotus, indicating that mitochondrial ROS might be more involved in the electron transport chain in the pistil than in the petal.

\section{Superoxide flashes in flowers}

To investigate the nature of superoxide flashes in magnolia and lotus, isolated mitochondria were loaded with the ROS fluorescent probe MitoSOX Red with $5 \mathrm{mM}$ succinate added as respiratory substrate. According to a previous study (Wang et al. 2016b), we defined the variation of fluorescence at $\mathrm{df} / \mathrm{F}_{0}>0.2$ within $10 \mathrm{~s}$ as a single superoxide flash event. A transient increase in MitoSOX fluorescence and variations in the trace were observed during $100 \mathrm{~s}$ in single mitochondrial events (Fig. 3A, B, and Video S1). Among these instantaneous traces, three types of mitochondrial superoxide traces were classified (Fig. 3C, D, E): low variation slope traces $\left(0.2<\mathrm{df} / \mathrm{F}_{0}<0.5\right)$ (Fig. $\left.3 \mathrm{C}\right)$, high variation slope traces $\left(0.5 \leq \mathrm{df} / \mathrm{F}_{0}\right)($ Fig. 3D), and multievent traces $\left(0.2<\mathrm{df} / \mathrm{F}_{0}\right)$ (Fig. 3E). We also compared the frequency of superoxide flashes $(/ 100 \mathrm{~s}$ $\times 1,000 \mu \mathrm{m}^{2}$ ) in mitochondria isolated from petals and pistils of magnolia and lotus. Notably, superoxide oxide flashes labelled with MitoSOX Red were detected at a rate of $129.18 \pm 20.11$ $\left(/ 100 \mathrm{~s} \times 1,000 \mu \mathrm{m}^{2}, \mathrm{n}=13\right)$ in mitochondria isolated from the magnolia style (Fig. 3F) which was significantly higher than mitochondria in the petal $\left(75.23 \pm 10.48 / 100 \mathrm{~s} \times 1,000 \mu \mathrm{m}^{2}, \mathrm{n}=\right.$ 11). In lotus (Fig. 3G), the rate of superoxide flashes was $48.24 \pm 10.24\left(/ 100 \mathrm{~s} \times 1,000 \mu \mathrm{m}^{2}, \mathrm{n}=\right.$ 10) in mitochondria isolated from the style, which was also significantly higher than mitochondria in the petal $\left(25.68 \pm 4.79 / 100 \mathrm{~s} \times 1,000 \mu \mathrm{m}^{2}, \mathrm{n}=10\right)$. These results indicate that superoxide flashes, together with ROS bursts, are highly autonomous and predominantly reflect the properties and physical activities of mitochondria in different tissues and species.

The MitoSOX-flashes were closely linked to functional ETC and respiratory activity. To observe the mitochondrial behavior in the change of respiration state and uncoupler, $0.25 \mathrm{mM}$ $\mathrm{ADP}$ and $5 \mu \mathrm{M}$ FCCP was added for the measurement of mitochondria isolated from style of 
265

266

267

268

269

270

271

272

273

274

275

276

277

278

279

280

281

282

283

284

285

286

287

288

289

290

Magnolia. The addition of ADP resulted in a significantly decrease in MitoSOX fluorescence (Fig B, D) (n=100). Mitochondrial respiratory uncoupled by FCCP also led to the significantly decrease in MitoSOX signal (Fig 4C, D) ( $\mathrm{n}=100)$. Similar behavior was found in the measurement of MitoSOX-flashes, the rate of superoxide flashes with succinate was significantly higher than mitochondria in the addition of ADP and FCCP (Fig 4E) $(n=6)$. Low flashes occurred in mitochondria upon uncoupling suggested that the electrical transmembrane gradient might modulate the superoxide flashes.

\section{Depolarization of the mitochondrial membrane potential in flowers}

To study variations in the $\Delta \Psi_{\mathrm{m}}$, isolated mitochondria were labelled with TMRM, and $5 \mathrm{mM}$ of succinate was added. The decline in fluorescent intensity at $\mathrm{df} / \mathrm{F}_{0}<-0.2$ was defined as an event. Transient depolarization of the $\Delta \Psi \mathrm{m}$ accompanied by later polarization occurred in a single mitochondrion (Fig. 5A, B and Video S2). According to the wide variation in $\Delta \Psi \mathrm{m}$, the trace $\Delta \Psi \mathrm{m}$ was catalogued into three types (Fig. $5 \mathrm{C}, \mathrm{D}, \mathrm{E}$ ): Instantaneous loss of $\Delta \Psi \mathrm{m}$ along with instant recovery (Fig. 5C), instantaneous loss of $\Delta \Psi \mathrm{m}$ with a short period of stability before recovery (Fig. 5D), and multi-event trace including the above two types (Fig. 5E). The frequency of a TMRM-event in mitochondria isolated from magnolia petals $(544.92 \pm 56.98 / 100 \mathrm{~s} \times 1,000$ $\left.\mu \mathrm{m}^{2}, \mathrm{n}=15\right)$ was significantly lower than the values in the style $(1,009.10 \pm 130.10 / 100 \mathrm{~s} \times$ $1,000 \mu \mathrm{m}^{2}, \mathrm{n}=15$ ) (Fig. 5G). The same result was found in lotus (Fig. 5F) that the frequency of TMRM events in mitochondria isolated from the lotus petal was $51.94 \pm 10.57(/ 100 \mathrm{~s} \times 1,000$ $\left.\mu \mathrm{m}^{2}, \mathrm{n}=10\right)$ which was lower than that in the receptacle $\left(119.99 \pm 19.00 / 100 \mathrm{~s} \times 1,000 \mu \mathrm{m}^{2}, \mathrm{n}=\right.$ 10). We conclude that transient and spontaneous depolarization of $\Delta \Psi \mathrm{m}$ occurred in all tissues and the higher frequency of variation of $\Delta \Psi \mathrm{m}$ in the pistils of flowers suggest that they have a higher level of mitochondrial dynamics. 
291 Discussion

292

293

294

295

296

297

298

299

300

301

302

303

304

305

306

307

308

309

310

311

312

313

314

315

316

317

Isolating mitochondria from plant tissues is complex and inefficient. In a previous study, the sucrose-based differential centrifugation method requires high-speed centrifugation $(40,000 \times \mathrm{g})$ and $300 \mathrm{~g}$ of sample within $5 \mathrm{~h}$ to obtain purified mitochondria (Day et al. 1985). Isolating mitochondria using the colloidal density gradient method consumes $60 \mathrm{~g}$ of sample and more than $4 \mathrm{~h}$ (Sweetlove et al. 2007). These methods are time- and sample-consuming, which may hinder the function and respiratory coupling of the mitochondria. In our method, we used only $0.5 \mathrm{~g}$ of floral tissues to obtain crude functional mitochondria in less than $1.5 \mathrm{~h}$ after centrifugation at a low speed $(\leq 12,000 \times \mathrm{g})$, which only required a standard laboratory centrifuge. A previous study reported that isolating crude mitochondria from leaves results in a higher RCR than when isolating purified mitochondria, which was consistent with our results (Keech et al. 2005). Since high mitochondrial respiration control ratio was prerequisite for superoxide flashes to occur (Schwarzlander et al. 2011), isolation of high viability mitochondria was necessary for the measurement of superoxide flashes. In the present study, we provide an effective and simple method to obtain highly viable mitochondria in different flower tissues to measure mitochondrial ROS, superoxide flashes and the $\Delta \Psi_{\mathrm{m}}$.

Mitochondrial ROS modulate various physiological events, including stress, growth, and cell death (Dickinson and Chang 2011; NavaneethaKrishnan et al. 2018; Sundaresan et al. 1995). Colocalization of ROS and mitochondria in polar growing pollen tubes reveals the production of $\mathrm{H}_{2} \mathrm{O}_{2}$ in mitochondria during pollen germination (Maksimov et al. 2018). Also, ROS are produced in mitochondria until the full flower bloom stage (Chakrabarty et al. 2007; Rogers 2012). Our study found good coincidence between the location of ROS and mitochondria in petals and pistils of two flower species (Fig. 2), indicating that ROS originate in mitochondria from floral tissues. ROS always act as signaling molecules to unlock the antioxidant system and maintain physiological activities in plants under salt stress (Ahanger et al. 2017). ROS are also involved in the energy-dissipating system that increases frost resistance in seedlings under freezing conditions (Grabelnych et al. 2014). And mitochondria contribute to ROS production 
318 through electron transfer from the respiratory chain in non-green tissues, such as flowers, and

319 ROS homeostasis is regulated by the antioxidant system (Rhoads et al. 2006; Rogers and Munne-

320 Bosch 2016). Considering the increased mitochondrial ROS production in pistils of magnolia

321

322

323

324

325

326

327

328

329

330

331

332

333

334

335

336

337

338

339

340

341

342

343

344

and lotus in our study, mitochondrial ROS might be more involved in the respiratory metabolic signaling pathways in the pistils of these two flower species.

An increase in ROS accumulation can trigger ROS burst in plants (Zandalinas and Mittler 2018), and basal mitochondrial ROS production is intimately linked with ROS flashes (Wang et al. 2012). The basal elevation of mitochondrial ROS triggers superoxide flashes (Hou et al. 2013). In our results, the simultaneous increase in ROS production and the frequency of superoxide flashes in the pistils indicated that increasing ROS production might trigger superoxide flashes. Superoxide flashes are involved in various stressful and pathophysiological conditions (Fang et al. 2011; Wang et al. 2013). Superoxide flashes are sensitive to mitochondrial respiration and a higher frequency of superoxide flash events acts as an early mitochondrial signal in response to physiological activities and oxidative stress (Ma et al. 2011; Wei et al. 2011). Superoxide flashes always respond to metabolic activities and act as a signal mediating disease (Cao et al. 2013; Wang et al. 2013). In addition, the frequency of superoxide flashes in early adulthood predicts the lifespan of an organism (Shen et al. 2014). Similarly, changes in superoxide flashes and fluorescence are closely related to respiratory activity in Arabidopsis and are affected by different respiratory substrates and inhibitors (Schwarzlander et al. 2011). Considering that superoxide flashes visualized by MitoSOX occurred at a similar frequency as cp-YFP-flashes in previous studies (Wang et al. 2016a; Zhang et al. 2013), our findings show that MitoSOX flashes in flower tissues reflect the nature of the flashes. An increase in the frequency of flashes in the pistil indicates that superoxide flashes together with mitochondrial ROS might be more involved in mitochondrial viability and physiological metabolism in flower pistils. Besides, superoxide flashes were strongly inhibited when electron transport was dysfunction (Wang et al. 2008). Superoxide flashes were markedly decreased by uncoupler of mitochondrial electron transport chain (Zhang et al. 2013). Also, the decrease of cp- 
345

346

347

348

349

350

351

352

353

354

355

356

357

358

359

360

361

362

363

364

365

366

367

368

369

370

YFP fluorescence caused by the addition of ADP and uncoupler FCCP was observed in mitochondria of Arabidopsis, which suggested the superoxide signal appeared to correlate with the magnitude of proton motive force (Schwarzlander et al. 2011). The decreasing of superoxide signal and flashes frequency in our study suggest that a strongly electrical transmembrane gradient is necessary for the production of superoxide flashes.

Spontaneous burst superoxide flashes are always consequential to the depolarization of mitochondrial $\Delta \Psi \mathrm{m}$ (Feng et al. 2017). A cp-YFP flash is always accompanied by depolarization of the $\Delta \Psi \mathrm{m}$ ( Li et al. 2012). The global rise in mitochondrial basal ROS can trigger the depolarization of $\Delta \Psi \mathrm{m}$ (Zorov et al. 2014) with further stimulation of ROS-induced ROS release resulting in an amplified ROS signal in response to oxidative challenge (Kuznetsov et al. 2017). Reversible variation of $\Delta \Psi \mathrm{m}$ is associated with the release of ROS under different physiological conditions (Kuznetsov et al. 2017). The simultaneous change in the frequency of superoxide flashes and depolarization of the mitochondrial membrane potential in our study suggest that superoxide flashes are always accompanied by fluctuations in the $\Delta \Psi \mathrm{m}$. Although the biogenesis of superoxide flashes is closely related to depolarization of the $\Delta \Psi \mathrm{m}$, the genesis of the flashes is not only related to $\Delta \Psi \mathrm{m}$ fluctuations. The incidence of $\Delta \Psi \mathrm{m}$ fluctuations is higher than that of superoxide flashes, because the cation and anion channels potentially contribute to fluctuation in the $\Delta \Psi \mathrm{m}$ (Wang et al. 2012). Thus, the higher rate of depolarization of $\Delta \Psi \mathrm{m}$ in our study suggests more ion exchange in mitochondria than the incidence of flashes.

\section{Conclusions}

In conclusion, our study presents an efficient method to isolate functional mitochondria to study superoxide flashes. Superoxide flashes visualized by MitoSOX reflect the nature of the flash. Moreover, the simultaneous increase in MitoSOX flashes and depolarization of $\Delta \Psi \mathrm{m}$ in mitochondria isolated from pistils demonstrate that mitochondria are involved in energy 
371 metabolism and physiological activities.

372

373

374

375

376

377

378

379

380

381 
382

383

384

385

386

387

388

389

390

391

392

393

394

395

396

397

398

399

400

401

402

403

404

405

406

407

408

409

410

411

412

413

414

415

416

417

418

419

420

421

\section{References}

Ahanger MA, Tomar NS, Tittal M, Argal S, Agarwal RM (2017) Plant growth under water/salt stress: ROS production; antioxidants and significance of added potassium under such conditions. Physiol Mol Biol Pla 23:731-744

Ahmed Z, Fu YB (2015) An improved method with a wider applicability to isolate plant mitochondria for mtDNA extraction. Plant methods 11:56

Cao YX, Zhang X, Shang W, Xu JJ, Wang XH, Hu XQ, Ao YF, Cheng HP (2013) Proinflammatory cytokines stimulate mitochondrial superoxide flashes in articular chondrocytes in vitro and in situ. PloS One 8:e66444

Chakrabarty D, Chatterjee J, Datta SK (2007) Oxidative stress and antioxidant activity as the basis of senescence in chrysanthemum florets. Plant Growth Regul 53:107-115

Day DA, Neuburger M., Douce R (1985) Biochemical characterrization of chlorophyll-free mitochondria from pea leaves. Aust J Plant Physio 12:219-228

Dickinson BC, Chang CJ (2011) Chemistry and biology of reactive oxygen species in signaling or stress responses. Nat Chem Biol 7:504-511

Fang HQ Chen M, Ding Y, Shang W, Xu JJ, Zhang X, Zhang WR, Li KT, Xiao Y, Gao F, Shang SJ, Li JC, Tian XL, Wang SQ, Zhou JS, Weisleder N, Ma JJ, Ouyang KF, Chen J, Wang XH, Zheng M, Wang W, Zhang XQ, Cheng HP (2011) Imaging superoxide flash and metabolism-coupled mitochondrial permeability transition in living animals. Cell Res 21:1295-1304

Feng G, Liu B, Hou T, Wang X, Cheng H (2017) Mitochondrial flashes: elemental signaling events in eukaryotic cells. Handb Exp Pharmacol 240:403-422

Grabelnych OI, Borovik OA, Tauson EL, Pobezhimova TP, Katyshev AI, Pavlovskaya NS, Koroleva NA, Lyubushkina IV, Bashmakov VY, Popov VN, Borovskii GB, Voinikov VK (2014) Mitochondrial energydissipating systems (alternative oxidase, uncoupling proteins, and external NADH dehydrogenase) are involved in development of frost-resistance of winter wheat seedlings. Biochemistry-Moscow + 79:506-519

Hatefi Y (1985) The mitochondrial electron transport and oxidative phosphorylation system. Annu Rev of Biochem 54:1015-1069

Hou TT, Zhang X, Xu JJ, Jian CS, Huang ZL, Ye T, Hu KP, Zheng M, Gao F, Wang XH, Cheng HP (2013) Synergistic triggering of superoxide flashes by mitochondrial $\mathrm{Ca}^{2+}$ uniport and basal reactive oxygen species elevation. J Biol Chem 288:4602-4612

Jastroch M (2017) Uncoupling protein 1 controls reactive oxygen species in brown adipose tissue. Proc Natl Acad Sci U S A 114:7744-7746

Keech O, Dizengremel P, Gardestrom P (2005) Preparation of leaf mitochondria from Arabidopsis thaliana. Physiol Plantarum 124:403-409

Keunen E, Schellingen K, Van Der Straeten D, Remans T, Colpaert J, Vangronsveld J, Cuypers A (2015) Alternative oxidase 1a modulates the oxidative challenge during moderate Cd exposure in Arabidopsis thaliana leaves. J Exp Bot 66:2967-2977

Kim HY, Botelho SC, Park KJ, Kim H (2015) Use of carbonate extraction in analyzing moderately hydrophobic transmembrane proteins in the mitochondrial inner membrane. Protein Sci 24:2063-2069

Kuznetsov AV, Javadov S, Saks V, Margreiter R, Grimm M (2017) Synchronism in mitochondrial ROS flashes, 
422

423

424

425

426

427

428

429

430

431

432

433

434

435

436

437

438

439

440

441

442

443

444

445

446

447

448

449

450

451

452

453

454

455

456

457

458

459

460

461

462 membrane depolarization and calcium sparks in human carcinoma cells. Biochimica et biophysica acta 1858:418-431

Li K, Zhang W, Fang H, Xie W, Liu J, Zheng M, Wang X, Wang W, Tan W, Cheng H (2012) Superoxide flashes reveal novel properties of mitochondrial reactive oxygen species excitability in cardiomyocytes. Biophys $\mathrm{J}$ 102:1011-1021

Luo SX, Chaw SM, Zhang DX, Renner SS (2010) Flower heating following anthesis and the evolution of gall midge pollination in Schisandraceae. Am J Bot 97:1220-1228

Lyu W, Selinski J, Li L, Day DA, Murcha MW, Whelan J, Wang Y (2018) Isolation and respiratory measurements of mitochondria from Arabidopsis thaliana. J Vis Exp 131:e56627

Ma Q, Fang HQ, Shang W, Liu L, Xu ZS, Ye T, Wang XH, Zheng M, Chen Q, Cheng HP (2011) Superoxide flashes early mitochondrial signals for oxidative stress-induced apoptosis. J Biol Chem 286:27573-27581

Maksimov N, Evmenyeva A, Breygina M, Yermakov I (2018) The role of reactive oxygen species in pollen germination in Picea pungens (blue spruce). Plant reproduction

Miller RE, Grant NM, Giles L, Ribas-Carbo M, Berry JA, Watling JR, Robinson SA (2011) In the heat of the night alternative pathway respiration drives thermogenesis in Philodendron bipinnatifidum. New Phytol 189:1013-1026

NavaneethaKrishnan S, Rosales JL, Lee KY (2018) Loss of Cdk5 in breast cancer cells promotes ROS-mediated cell death through dysregulation of the mitochondrial permeability transition pore. Oncogene 37:1788-1804

Paital B, Chainy GB (2014) Effects of temperature on complexes I and II mediated respiration, ROS generation and oxidative stress status in isolated gill mitochondria of the mud crab Scylla serrata. J Therm Biol 41:104111

Pouvreau S (2010) Superoxide flashes in mouse skeletal muscle are produced by discrete arrays of active mitochondria operating coherently. PloS One 5:4439-4451

Rhoads DM, Umbach AL, Subbaiah CC, Siedow JN (2006) Mitochondrial reactive oxygen species. Contribution to oxidative stress and interorganellar signaling. Plant Physiol 141:357-366

Rogers H, Munne-Bosch S (2016) Production and scavenging of reactive oxygen species and redox signaling during leaf and flower senescence: similar but different. Plant Physiol 171:1560-1568

Rogers HJ (2012) Is there an important role for reactive oxygen species and redox regulation during floral senescence? Plant Cell Environ 35:217-233

Schwarzlander M, Logan DC, Fricker MD, Sweetlove LJ (2011) The circularly permuted yellow fluorescent protein cpYFP that has been used as a superoxide probe is highly responsive to $\mathrm{pH}$ but not superoxide in mitochondria: implications for the existence of superoxide 'flashes'. Biochem J 437:381-387

Shen EZ, Song CQ, Lin Y, Zhang WH, Su PF, Liu WY, Zhang P, Xu JJ, Lin N, Zhan C, Wang XH, Shyr Y, Cheng HP, Dong MQ (2014) Mitoflash frequency in early adulthood predicts lifespan in Caenorhabditis elegans. Nature 508:128-132

Sundaresan M, Yu ZX, Ferrans VJ, Irani K, Finkel T (1995) Requirement for generation of $\mathrm{H}_{2} \mathrm{O}_{2}$ for platelet-derived growth factor signal transduction. Science 270:296-299

Sweetlove LJ, Taylor NL, Leaver CJ (2007) Isolation of intact, functional mitochondria from the model plant Arabidopsis thaliana. Methods Mol Biol 372:125-136

Thien LB, Bernhardt P, Devall MS, Chen ZD, Luo YB, Fan JH, Yuan LC, Williams JH (2009) Pollination biology of basal angiosperms (Anita Grade). Am J Bot 96:166-182

PeerJ reviewing PDF | (2018:11:33136:1:1:NEW 22 Feb 2019) 
463

464

465

466

467

468

469

470

471

472

473

474

475

476

477

478

479

480

481

482

483

484

485

486

487

488

489

Wang JQ, Chen Q, Wang XH, Wang QC, Wang Y, Cheng HP, Guo CX, Sun QM, Chen Q, Tang TS (2013) Dysregulation of mitochondrial calcium signaling and superoxide flashes cause mitochondrial genomic DNA damage in Huntington Disease. J Biol Chem 288:3070-3084

Wang W, Fang H, Groom L, Cheng A, Zhang W, Liu J, Wang X, Li K, Han P, Zheng M, Yin J, Wang W, Mattson MP, Kao JP, Lakatta EG, Sheu SS, Ouyang K, Chen J, Dirksen RT, Cheng H (2008) Superoxide flashes in single mitochondria. Cell 134:279-290

Wang W, Gong GH, Wang XH, Wei-LaPierre L, Cheng HP, Dirksen R, Sheu SS (2016a) Mitochondrial flash: integrative reactive oxygen species and $\mathrm{pH}$ signals in cell and organelle biology. Antioxid Redox Sign 25:534-549

Wang X, Jian C, Zhang X, Huang Z, Xu J, Hou T, Shang W, Ding Y, Zhang W, Ouyang M, Wang Y, Yang Z, Zheng M, Cheng H (2012) Superoxide flashes: elemental events of mitochondrial ROS signaling in the heart. J Mol Cell Cardiol 52:940-948

Wang X, Zhang X, Huang Z, Wu D, Liu B, Zhang R, Yin R, Hou T, Jian C, Xu J, Zhao Y, Wang Y, Gao F, Cheng H (2016b) Protons trigger mitochondrial flashes. Biophys J 111:386-394

Wei L, Dirksen RT (2012) Perspectives on: SGP symposium on mitochondrial physiology and medicine: mitochondrial superoxide flashes: from discovery to new controversies. J Gen Physiol 139:425-434

Wei L, Salahura G, Boncompagni S, Kasischke KA, Protasi F, Sheu SS, Dirksen RT (2011) Mitochondrial superoxide flashes: metabolic biomarkers of skeletal muscle activity and disease. Faseb J 25:3068-3078

Yang JL, Mukda S, Chen SD (2018) Diverse roles of mitochondria in ischemic stroke. Redox biology 16:263-275

Yang Y, Karakhanova S, Hartwig W, D'Haese JG, Philippov PP, Werner J, Bazhin AV (2016) Mitochondria and mitochondrial ROS in cancer: novel targets for anticancer therapy. J Cell Physiol 231:2570-2581

Zandalinas SI, Mittler R (2018) ROS-induced ROS release in plant and animal cells. Free Radical Bio Med 122:2127

Zhang X, Huang Z, Hou T, Xu J, Wang Y, Shang W, Ye T, Cheng H, Gao F, Wang X (2013) Superoxide constitutes a major signal of mitochondrial superoxide flash. Life sciences 93:178-186

Zorov DB, Juhaszova M, Sollott SJ (2014) Mitochondrial reactive oxygen species (Ros) and Ros-Induced Ros Release. Physiol Rev 94:909-950 


\section{Figure 1}

Sampling and detection of isolated mitochondria.

Sampling of Magnolia denudata (A) and Nelumbo nucifera (F). Detection of auto-fluorescence of intact chloroplasts in $M$. denudata (B) and $N$. nucifera (G). Viability of isolated mitochondria in petal $(C)$ and style (D) of $M$. denudata, petal $(\mathrm{H})$ and receptacle $(\mathrm{I})$ of $N$. nucifera using our efficiency method A (crude isolated mitochondria). Viability of mitochondria isolated from style in $M$. denudata (E) and from receptacle in $N$. nucifera $(\mathrm{J})$ using method B (density gradient-purified mitochondria). Pe: petal, Gy: gynoecium, Rec: receptacle. Scale bar: $5 \mu \mathrm{m}$.(All photoes were taken by Chulan Zhang).

*Note: Auto Gamma Correction was used for the image. This only affects the reviewing manuscript. See original source image if needed for review.

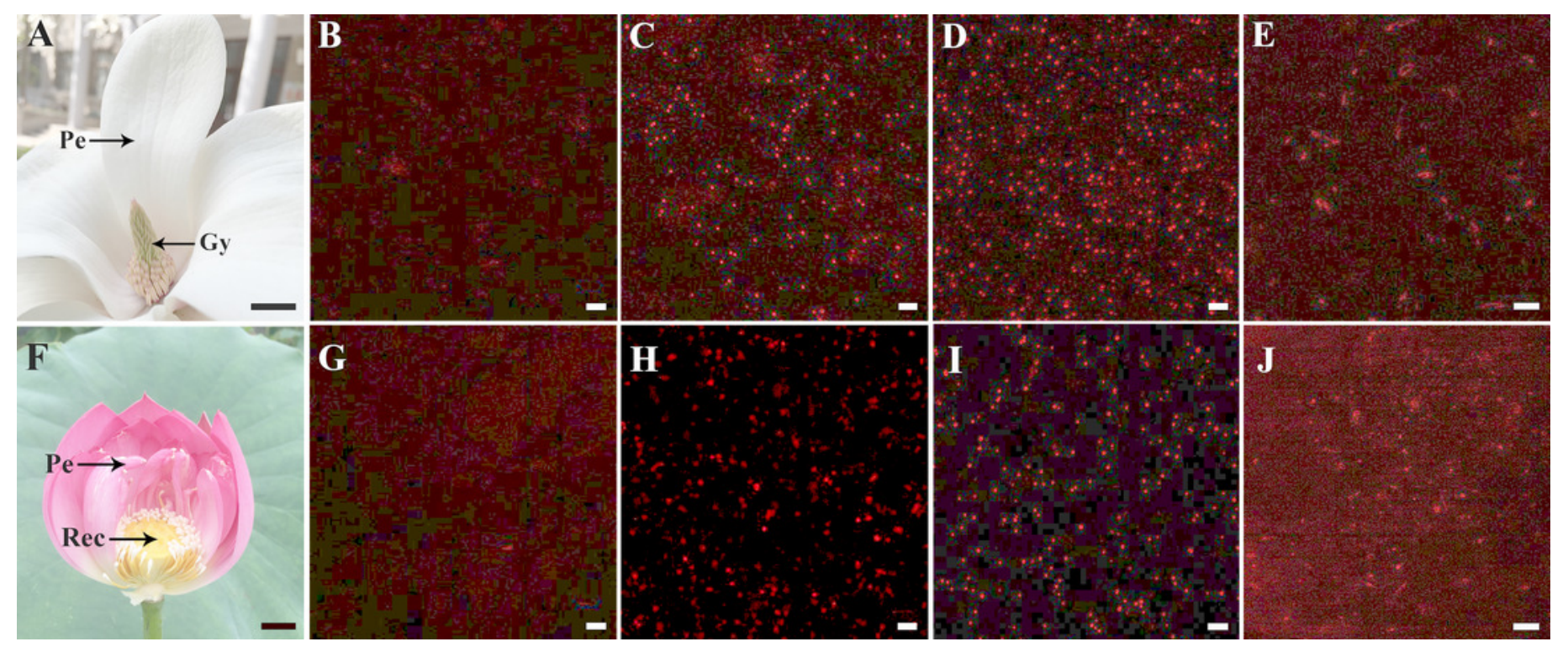




\section{Figure 2}

ROS production and colocalization with mitochondria.

ROS production and colocalization with mitochondria isolated from M. denudata:

mitochondria isolated from petal $(A)$ and style $(E)$ were visualized by Mito Tracker Green (in green color), mitochondrial ROS in mitochondria isolated from petal (B) and mitochondria isolated from style (F) was visualized by MitoSOX red (in red color), colocalization of ROS and mitochondria in petal (C) and style (G). D. Comparison of ROS fluorescent intensity in petal and style of $M$. denudata. ROS production and colocalization with mitochondria isolated from N. nucifera: mitochondria isolated from petal $(\mathrm{H})$ and receptacle $(\mathrm{L})$ were visualized by Mito Tracker Green (in green color), mitochondrial ROS in mitochondria isolated from petal (I) and mitochondria isolated from style (M) was visualized by MitoSOX red (in red color), colocalization of ROS and mitochondria in petal (J) and receptacle (N). K. Comparison of ROS fluorescent intensity in petal and receptacle of $N$. nucifera. Scale bar: $5 \mu \mathrm{m}$. 

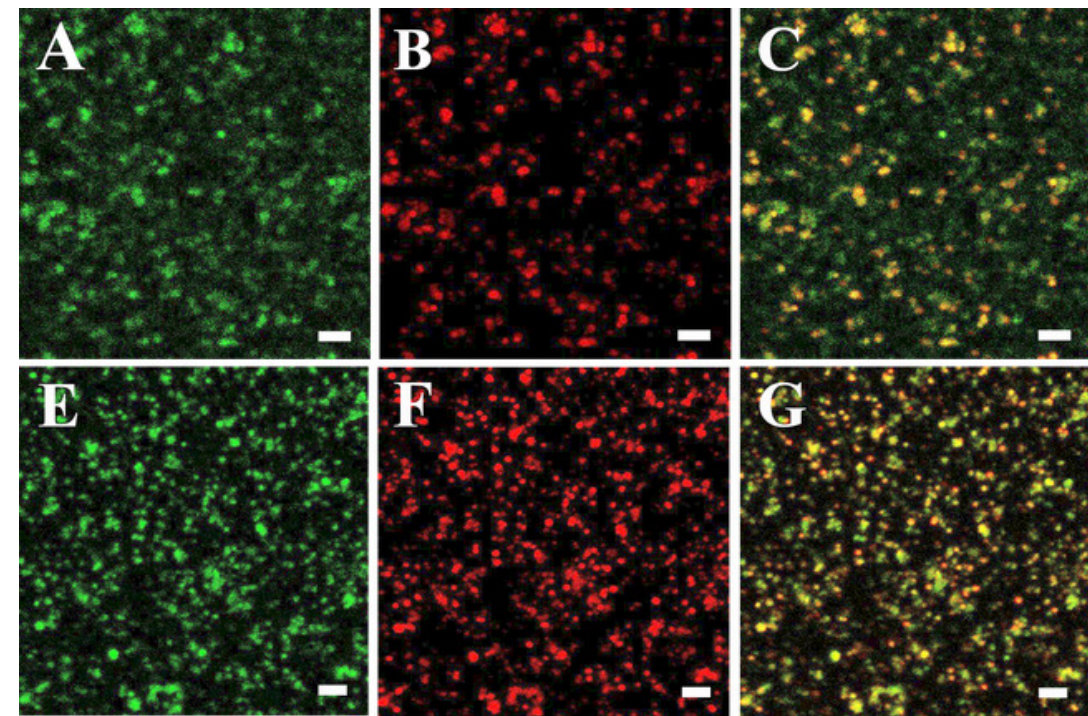

D
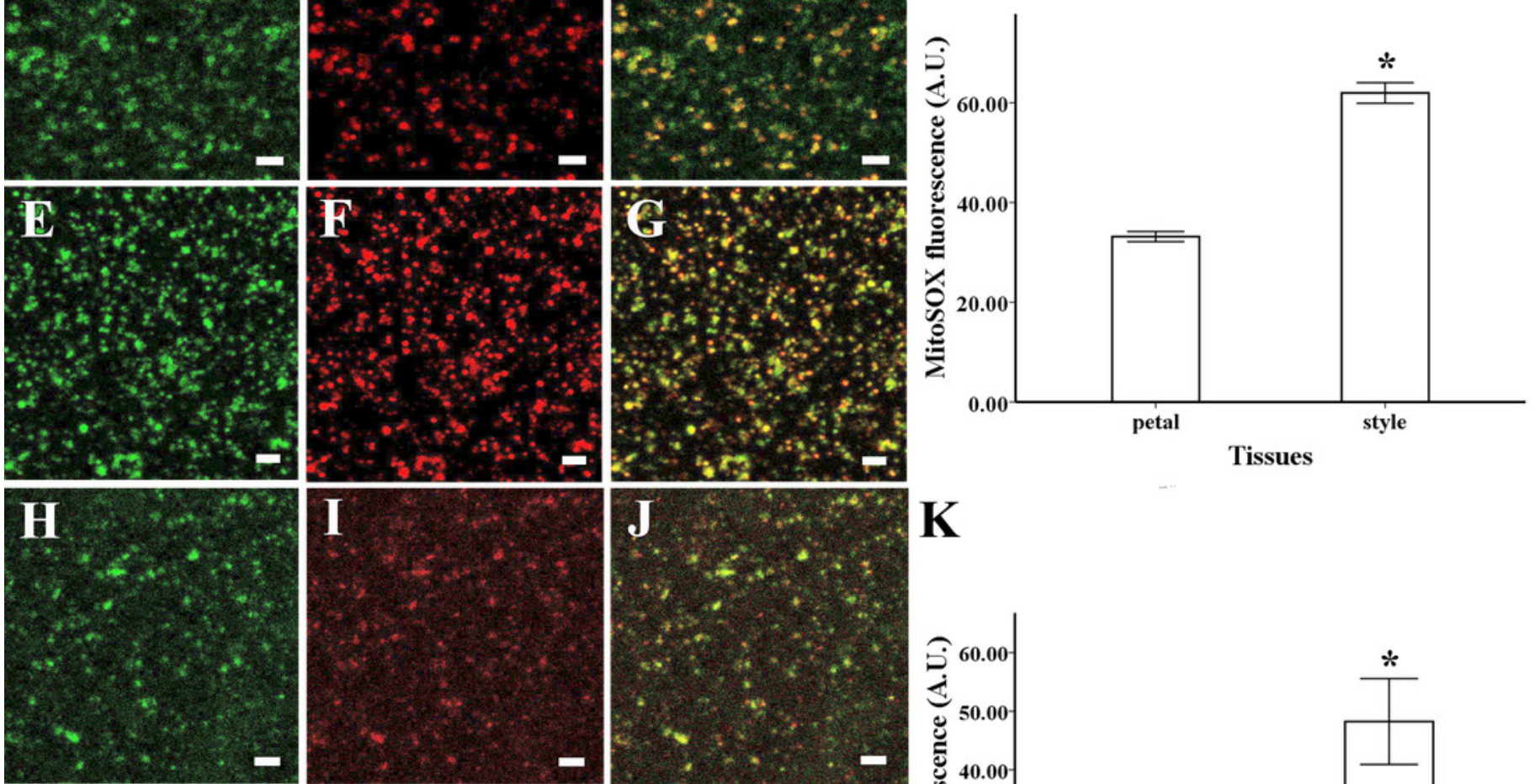

\section{K}
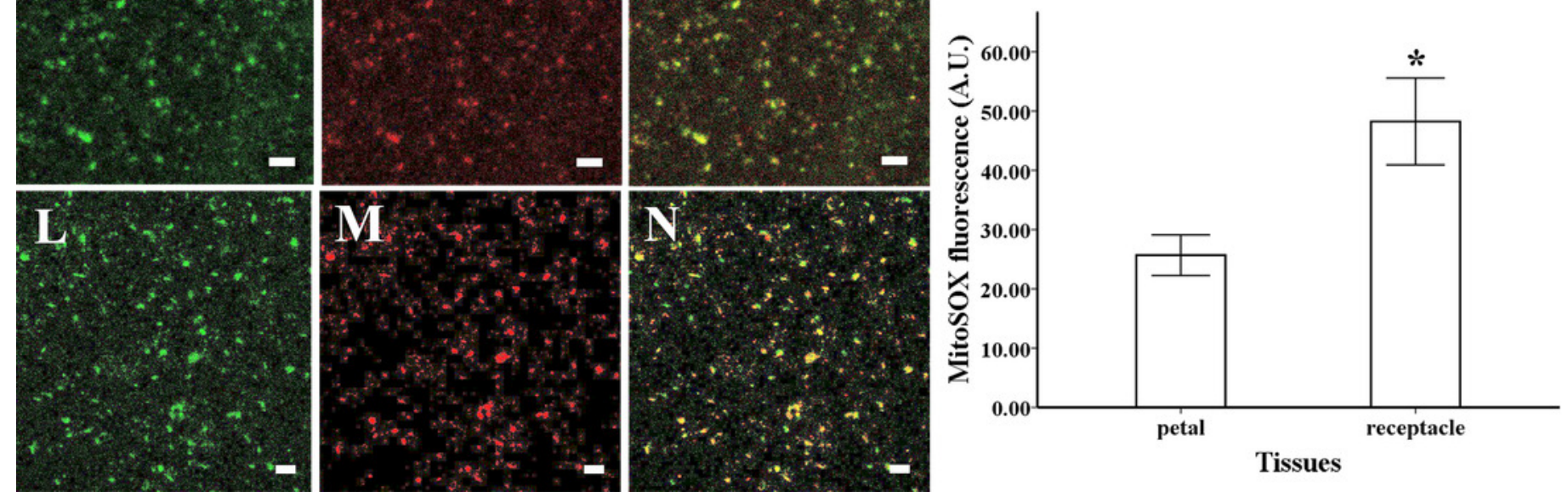


\section{Figure 3}

Superoxide flashes visualized by MitoSOX and flashes frequency.

A. Isolated mitochondria labeled with MitoSOX red. B. Time-lapse images (upper) and typical trace (lower panel) of superoxide flashes visualized by MitoSOX red. Different types of traces of superoxide flashes (C) low variation slope traces, (D) high variation slope traces, (E) multievent traces. F. Comparison of superoxide flashes frequency in mitochondria isolated from petal and style of $M$. denudata. G. Comparison of superoxide flashes frequency in mitochondria isolated from petal and receptacle of $N$. nucifera. Scale bar: $5 \mu \mathrm{m}$.

*Note: Auto Gamma Correction was used for the image. This only affects the reviewing manuscript. See original source image if needed for review. 

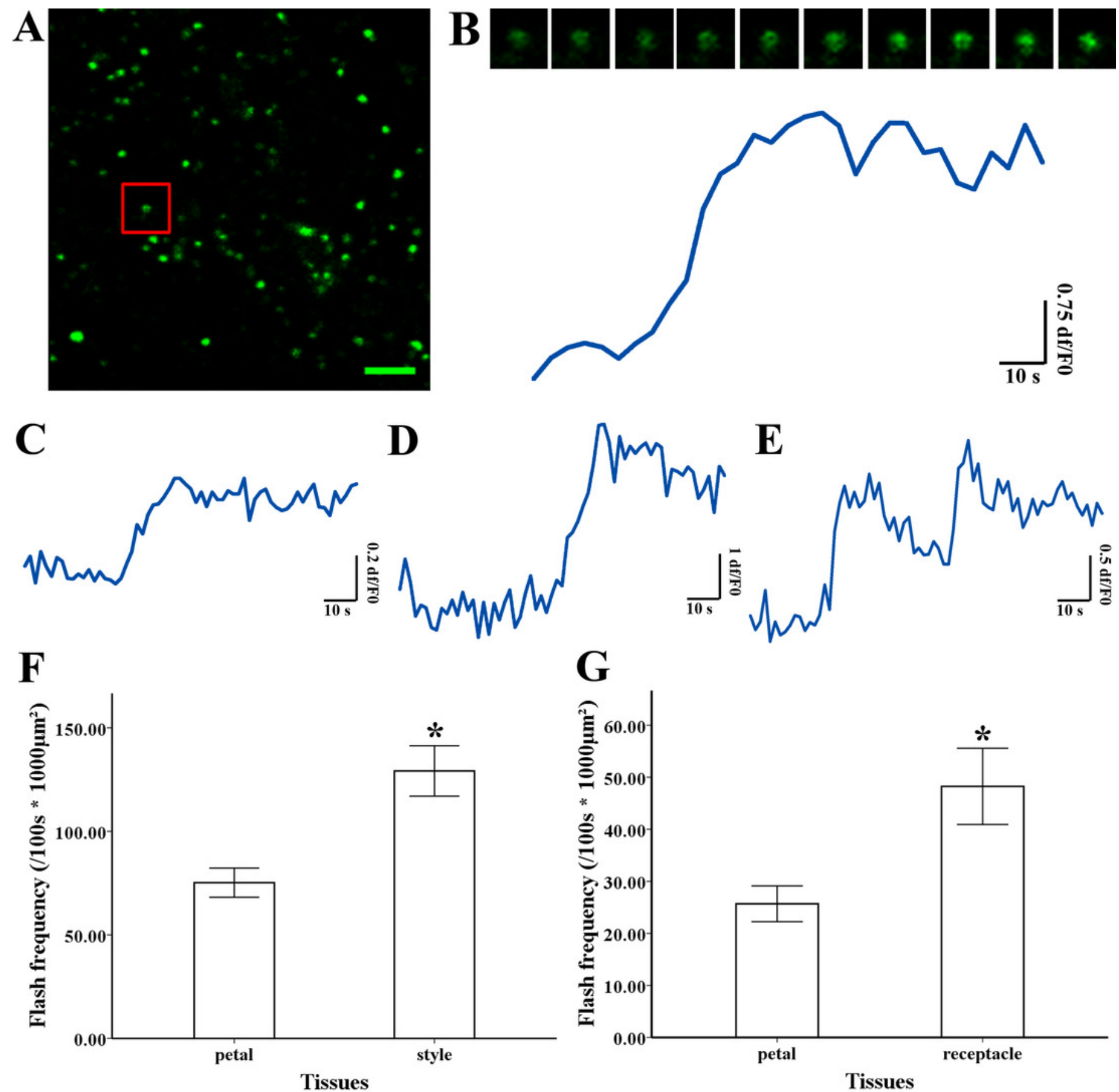


\section{Figure 4}

ROS production and superoxide flashes in different respiratory substrate.

Isolated mitochondria from style of $M$. denudata labeled with MitoSOX red (A) $5 \mathrm{mM}$ succinate, (B) $5 \mathrm{mM}$ succinate and $250 \mu \mathrm{M} \mathrm{ADP}$, (C) $5 \mathrm{mM}$ succinate and $5 \mu \mathrm{M}$ FCCP.

Comparison of ROS production and superoxide flashes frequency in mitochondria isolated from style of $M$. denudata in different respiratory substrate: (D). Comparison of mitochondrial ROS fluorescent intensity in different respiratory substrate. (E). Comparison of mitochondrial superoxide flashes frequency in different respiratory substrate. succ: succinate. Scale bar: $5 \mu \mathrm{m}$.

*Note: Auto Gamma Correction was used for the image. This only affects the reviewing manuscript. See original source image if needed for review.
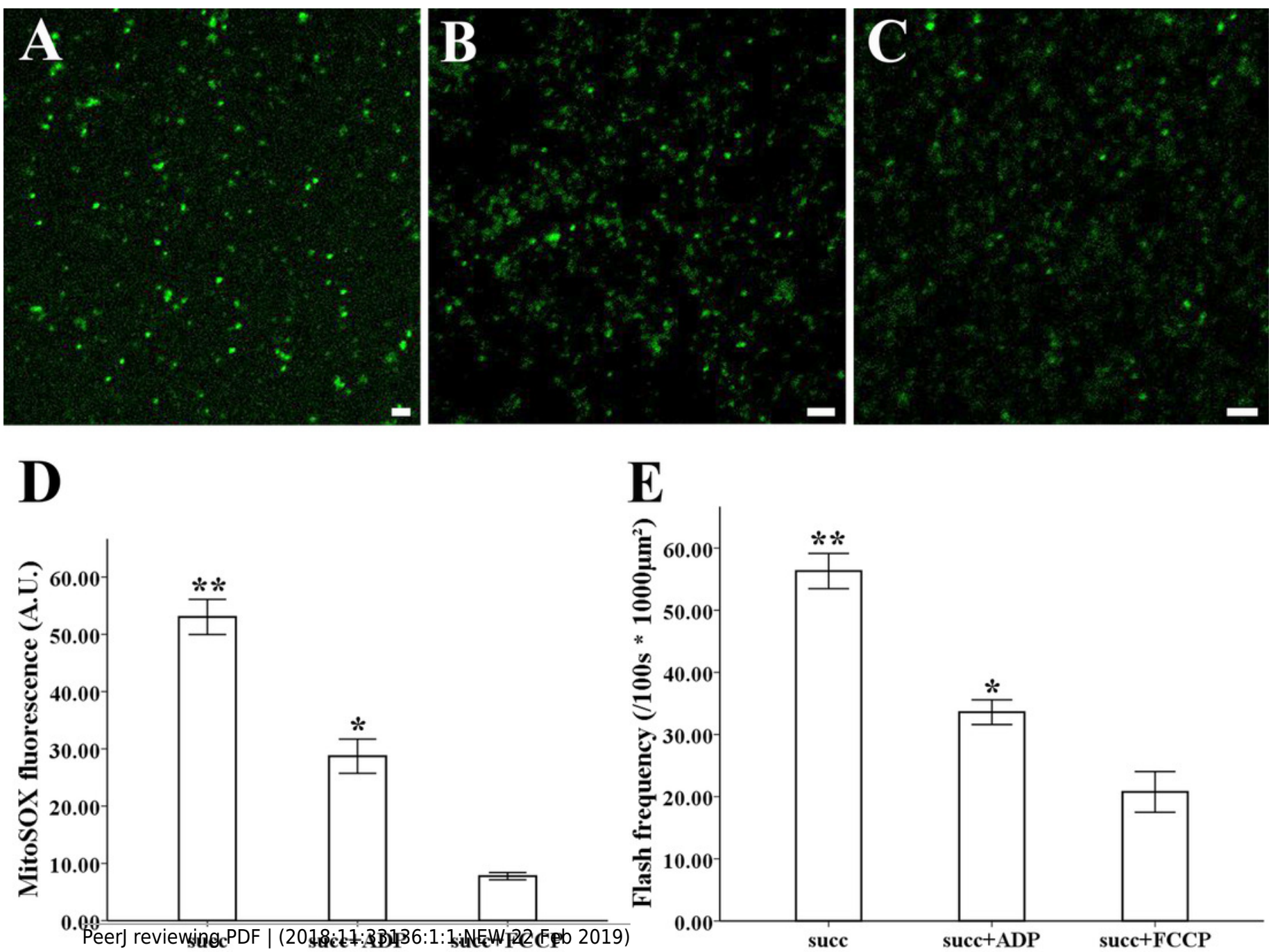


\section{Figure 5}

Depolarization of mitochondria membrane potential $\left(\Delta \Psi_{\mathrm{m}}\right)$ and frequency.

A. Isolated mitochondria labeled by TMRM. B. Time-lapse images (upper) and typical trace (lower panel) of depolarization of $\Delta \Psi \mathrm{m}$ labeled by TMRM. Different types of trace of TMRM (C) instantaneous loss and recovery of $\Delta \Psi_{\mathrm{m}},(\mathrm{D})$ instantaneous loss with the short period of stability before recovery of $\Delta \psi_{m}$, (E) multi-event traces. Comparison of depolarization of $\Delta \Psi \mathrm{m}$ frequency in mitochondria isolated from petal and style of $N$. nucifera $(F)$. Comparison of depolarization of $\Delta \Psi \mathrm{m}$ frequency in mitochondria isolated from petal and receptacle of $\mathrm{M}$. denudata (G). Scale bar: $5 \mu \mathrm{m}$.

*Note: Auto Gamma Correction was used for the image. This only affects the reviewing manuscript. See original source image if needed for review. 

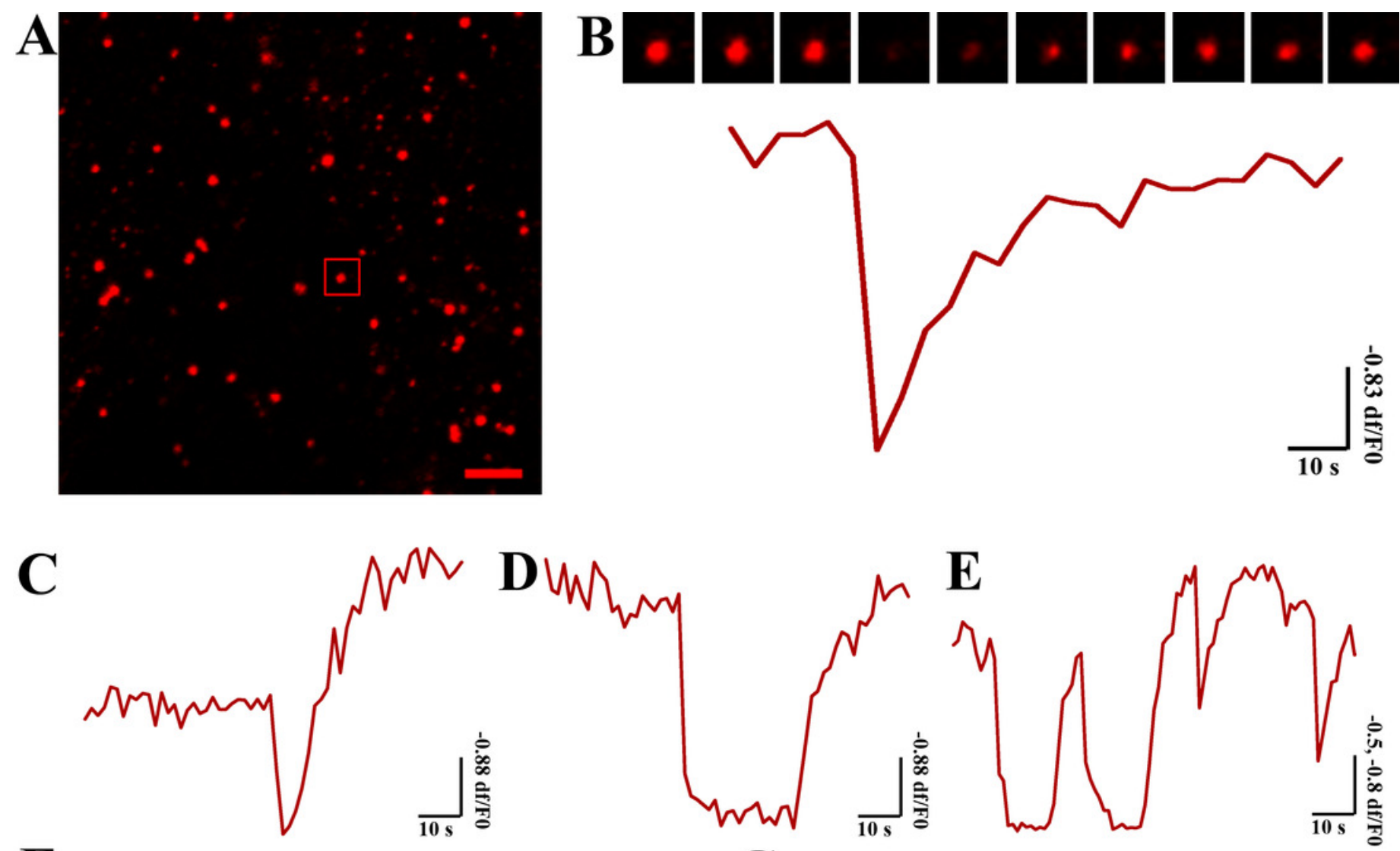

F

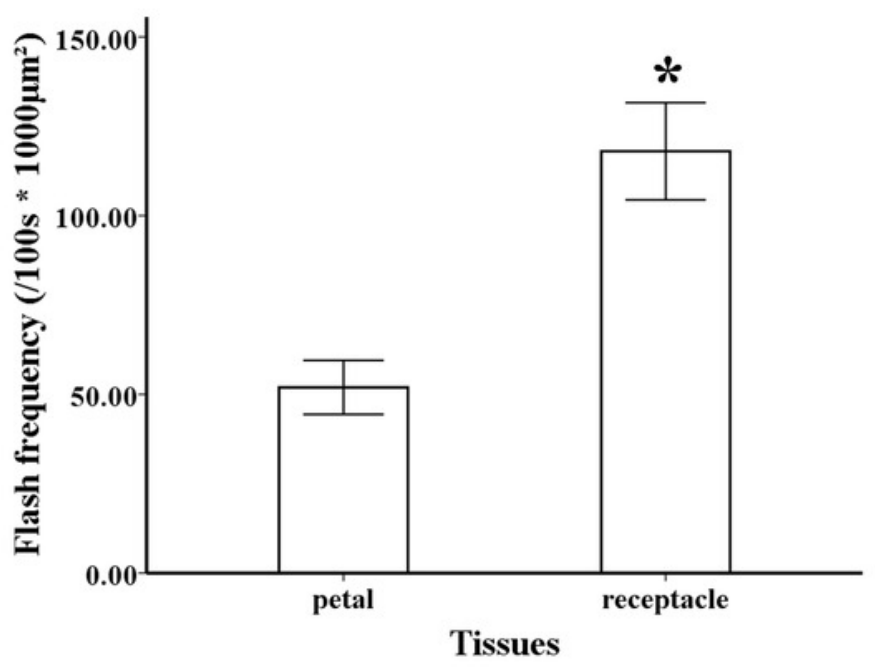

G

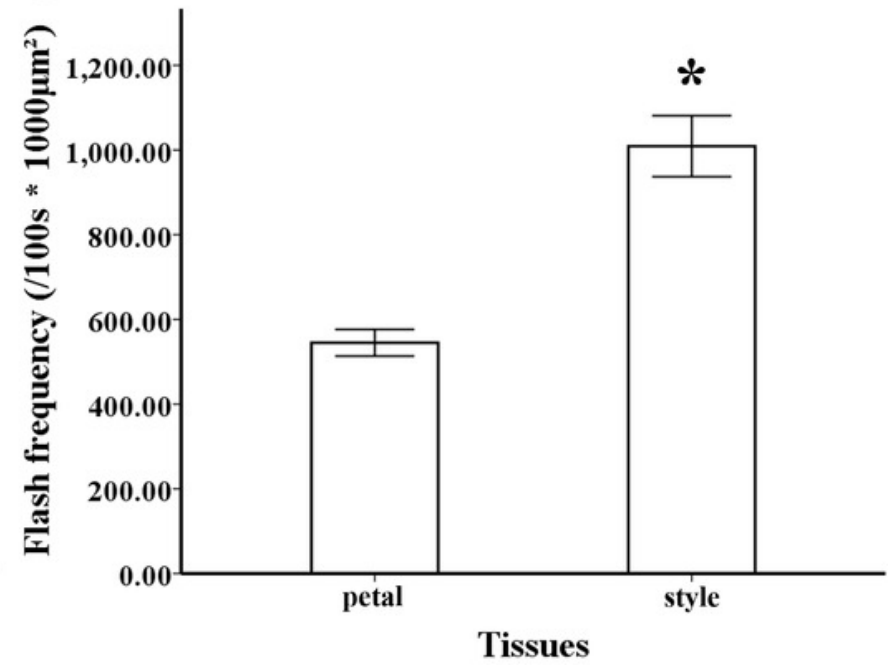




\section{Table $\mathbf{1}$ (on next page)}

Respiratory function of isolated mitochondria.

Respiratory function of isolated mitochondria isolated from pistils and petal tissues of Magnolia denudata and Nelumbo nucifera with our efficiency method A (crude isolated mitochondria) and respiration function of isolated mitochondria from style of Magnolia denudata with previous method B (density gradient-purified mitochondria). Values are mean \pm S.D., $n=6$. 
1

2

Table 1

Respiratory function of isolated mitochondria with our method A and previous method B

\begin{tabular}{llll}
\hline Groups & State $3 \mathrm{nmol} \mathrm{O} \cdot \mathrm{min}^{-1} \cdot \mathrm{mg}^{-1}$ & State $4 \mathrm{nmol} \mathrm{O} \cdot \mathrm{min}^{-1} \cdot \mathrm{mg}^{-1}$ & $\mathrm{RCR}$ \\
\hline Stigma (M. denudata) & $269.68 \pm 28.49$ & $60.08 \pm 6.13$ & $4.49 \pm 0.20^{\mathrm{a}}$ \\
Petal (M. denudata) & $276.06 \pm 31.50$ & $64.46 \pm 7.88$ & $4.29 \pm 0.16^{\mathrm{ab}}$ \\
Receptacle (N.nucifera) & $257.73 \pm 34.91$ & $60.00 \pm 8.59$ & $4.30 \pm 0.21^{\mathrm{ab}}$ \\
Petal (N.nucifera) & $259.14 \pm 33.82$ & $61.99 \pm 8.68$ & $4.19 \pm 0.25^{\mathrm{b}}$ \\
Method B & $243.90 \pm 35.01$ & $61.89 \pm 8.39$ & $3.94 \pm 0.18^{\mathrm{c}}$ \\
\hline
\end{tabular}

Values are mean \pm S.D., $\mathrm{n}=6$.

3

4 